\title{
Implementation strategies, and barriers and facilitators for implementation of physical activity at work: a scoping review
}

\author{
Anne Garne-Dalgaard ${ }^{1,2^{*}}$ (D), Stephanie Mann ${ }^{1}$, Thomas Viskum Gjelstrup Bredahl ${ }^{1}$ and \\ Mette Jensen Stochkendahl $1^{1,2}$
}

\begin{abstract}
Background: Inactivity and sedentary lifestyle have led experts to recommend an increase in structured, workplacebased physical activity (PA) initiatives. Previous studies on workplace-based PA have only shown moderate and short-term effects. This has been attributed to the lack of clear implementation strategies and understanding of factors that may hinder or enable uptake of PA. To ensure long-term, sustainable outcomes, there is a need for a better understanding of implementation strategies, and barriers and facilitators to workplace-based PA.

Method: A scoping review of studies investigating implementation approaches and factors affecting uptake of workplace-based PA was conducted. Qualitative and quantitative articles published in MEDLINE, Embase, Scopus, or PsycINFO between 2008 and 2018 evaluating the implementation of PA were included. Data on study characteristics, evaluation, and implementation methods applied were systematically extracted. Two reviewers extracted, coded, and organised factors affecting uptake using the Theoretical Domains Framework (TDF).

Results: After dual, blinded screening of titles and abstracts, 16 articles reporting on eight studies were included in the review. Several different methods of implementation were applied, including information meeting, kick-off events, and "change agents" as the most common. A total of 109 factors influencing implementation were identified, consisting of 57 barriers and 52 facilitators. Barriers most often related to the TDF domains Environmental Context and Resources $(n=34,36.2 \%)$, Social influences $(n=13,13.8 \%)$, and Social/Professional Role and Identity $(n=8$, 8.5\%). Likewise, facilitators most often related to the TDF domains Social influences ( $n=17,19.5 \%)$, Environmental Context and Resources $(n=16,18.4 \%)$, and Social/Professional Role and Identity $(n=9,10.3 \%)$.

Conclusion: Our review has highlighted the multilevel factors affecting the uptake of workplace-based PA and underpins the complexities in implementation of such initiatives. The published literature predominantly provides details from the employees' perspectives on factors that need to be addressed and a lack of attention to these factors will cause them to hamper uptake of PA. The analysis of barriers and facilitators provides a theoretical foundation to guide future intervention design. However, further research is needed to fully understand the success or failure of implementation processes.
\end{abstract}

Keywords: Implementation, Physical activity, Workplaces, Theoretical Domains Framework, Barriers, Facilitators, Scoping review

\footnotetext{
* Correspondence: a_dal_2@hotmail.com

${ }^{1}$ Department of Sports Science and Clinical Biomechanics, University of

Southern Denmark, Odense, Denmark

${ }^{2}$ Nordic Institute of Chiropractic and Clinical Biomechanics, Odense, Denmark
}

(c) The Author(s). 2019 Open Access This article is distributed under the terms of the Creative Commons Attribution 4.0 International License (http://creativecommons.org/licenses/by/4.0/), which permits unrestricted use, distribution, and reproduction in any medium, provided you give appropriate credit to the original author(s) and the source, provide a link to the Creative Commons license, and indicate if changes were made. The Creative Commons Public Domain Dedication waiver (http://creativecommons.org/publicdomain/zero/1.0/) applies to the data made available in this article, unless otherwise stated. 


\section{Background}

Physical activity (PA) has been considered as health enhancing for decades, with health authorities advising that PA should be part of daily life throughout the lifespan. Most of the adult working population spends a great deal of their time at work, and general changes in working environments have increased time spent on sedentary work [1]. Inactivity and sedentary lifestyles have been estimated to cause over 1 million deaths annually in Europe [2], which have led experts to recommend an increase in structured PA embedded in modern work activities [3]. This has changed the focus on workplaces from being an arena for work-related activities only, to also becoming a potential field for implementing PA and other types of health promoting initiatives.

To mirror this shift in focus, recent studies have evaluated the effect of a variety of PA programmes in the workplace. Positive, moderate, short-term health enhancing benefits have been documented for the cardiovascular system [4-6], the metabolism [5, 6], musculoskeletal pain and function [7-11], and mental health and general wellbeing $[12,13]$. In addition, moderate evidence also points towards a positive effect of workplace health promotion on work ability $[4,12,13]$.

When it comes to the impact of workplace PA on other types of work performance outcomes, like productivity $[14,15]$, presenteeism [16], and work absence [12, 13], the evidence is sparser and the results inconsistent [14-16]. Recent randomised controlled trials (RCT) have not provided conclusive evidence of the effect on work performance outcomes $[4,5,7]$, but indicate that attending PA during working hours does, at least, not appear to have negative effects on work productivity $[4,5]$.

Workplace-based PA encompasses a wide range of activities of various duration, intensity, and mode of delivery. But a common feature is the targeted nature of these activities to the needs of the individuals beyond general advice about health enhancing behaviors. In 2015, Pereira et al. identified eight workplace-based RCTs, which encompassed such diverse PA programs as strength training, aerobic training, combinations of the two, activities targeting flexibility, different types of walking programs, yoga, and tai chi [14]. In Denmark, no less than 15 RCTs have been conducted, which have tested the concept of intelligent physical exercise training (IPET) [5]. IPET is delivered as individually tailored PA to match the individual's work exposure, health status, and physical capacity, and it includes aerobic training, strength training targeting e.g., neck and shoulder muscles, core stability training, and balance training [5]. IPET has been tested in various working groups with varying effects [5]. Improvements in musculoskeletal pain were mostly found among office workers, dentists, industrial laboratory technicians, cleaners, and fighter pilots, whereas improvements in the cardio-metabolic systems were mostly seen among office workers, healthcare workers, and construction workers [5].

When positive, the effects of PA appear to be only modest and short-term. One reason being that implementation and adherence to workplace PA has proven difficult [17-19]. As an example, the mean level of regular adherence was $61 \%$ across nine RCTs conducted in Denmark, ranging from $31 \%$ to $86 \%$ [17]. Baily et al. systematically reviewed barriers and facilitators for implementation of workplace physical activity policies and found that not having a clear company policy on workplace PA is a vital barrier for implementation [20]. Other researchers have suggested that the suboptimal results of implementation of general health enhancing interventions could be due to limited use of a theoretical foundation to underpin such interventions $[21,22]$. Several implementation theories, models, and frameworks exist, which may provide better understanding and explanation of how and why implementation succeeds or fails [21]. Nilsen suggests the use of determinant frameworks to describe factors that impact implementation outcomes, i.e., factors that either impede or enable uptake [21]. One of these determinant frameworks is the widely used Theoretical Domains Framework (TDF). TDF is a comprehensive synthesis of theories of behaviour and behaviour change [23, 24]. It is a multilevel framework, which allows identification of determinants at different levels, from the individual user, to the organization and beyond [21]. Like many other determinant frameworks, it does not specify causal mechanisms, but provides potentially useful information for designing and executing implementation strategies [21].

Despite comprehensive research on PA in workplaces, the implementation and sustainability of such initiatives are still challenging and need more attention [9, 16, 17]. During the last 30 years, there has been important development in the content, performance, and organization of work in many industries. At the same time, significant changes in workers' health have occurred. In 2009, a systematic review by Robroek et al. [25] investigated determinants of participation in general worksite health promotion programs. The interventions consisted of education or counselling as main component, introductions of a fitness center or exercise facilities, or multi-component programs. The authors evaluated determinants of participation at individual, workplace and intervention type levels. They found large variations in participation levels, and only female sex was associated with higher participation in the pooled analyses. This led Robroek et al. to conclude: "Few studies evaluated the influence of health, lifestyle and work-related factors on participation, which hampers the insight in the underlying determinants of initial participation in worksite health promotion" [25]. To ensure long-term, sustainable implementation of workplace-based PA, there is a need for a better understanding of implementation strategies, and the 
barriers and facilitators that impact uptake of workplace PA interventions. A greater insight into these factors would enhance the opportunity to more accurately tailor interventions and thereby, increase the opportunity of successful implementation and long-lasting effects on employees' health and well-being, and workplace performance outcomes.

Therefore, the aim of this scoping review is to descriptively summarize implementation approaches for workplace-based PA, and to identify and organise barriers and facilitators affecting the uptake of the workplace-based PA using TDF.

\section{Method}

\section{Study design}

This scoping review is reported according to the Preferred Reporting Items for Systematic Reviews and Meta-Analyses Extension for Scoping Reviews (PRISMA-ScR) [26].

\section{Information sources and search strategy}

A systematic search of the following databases was undertaken: Embase, MEDLINE, Scopus, and PsycINFO. All databases were searched from 2008 until March 2018. Reference and citation searching were also undertaken. The searches were performed by the first author, who was guided by an experienced information specialist from the library at the University of Southern Denmark.

The search strategy included subject indexing terms and free-text terms for title, abstract, and keyword searching. The research question directed the entire literature search, and based on this, the search terms were grouped into three concepts and arranged in accordance to relevance in a search matrix: 1) implementation, 2) physical activity, and 3) workplaces. Search terms under each of the three concepts were selected from keywords identified in a preliminary search in PubMed and the list of Medical Subject Headings (MeSH), and after discussion with the review team. The full version of the search terms used, including specifications on use of title, keywords, or abstract screening, is documented in Additional file 1. In all four databases, the search was performed according to the block search method using the Boolean operators "OR" and "AND". To maintain an overview throughout the literature search, a search protocol was continually populated with all search terms, number of hits, and combination of searches (Additional file 1).

\section{Study selection}

All identified citations from the searched databases were uploaded to EndNote $\times 8$ software. An integrated duplication detection tool was used to identify duplicates. All suggested duplicate pairs were screened for correctness by one reviewer (AGD). Title and abstract screenings were performed for each article by two independent reviewers (AGD and SM) [27]. Disagreement between the two reviewers resulted in inclusion of the citation to full-text screening. Full-text screening was similarly performed by two independent reviewers (AGD and SM) assessing the eligibility of the citation. Any disagreements were resolved through discussion mediated by a third reviewer (MJS) [27].

The eligibility criteria for the original studies are presented in Table 1. Unlike systematic reviews and meta-analyses, the eligibility does not necessarily have to be established before the literature search in a scoping review. These can be developed as the knowledge of the identified literature grows [29]. In accordance with this approach, the eligibility criteria for this scoping review were adjusted after the screening of the titles. Interventions relating to return-to-work, sickness absence management, and occupational safety were added to the exclusion criteria, due to irrelevance in accordance with the review focus.

\section{Data collection}

Similar to the study selection process, data extraction was performed independently by two reviewers (AGD and SM) using predefined data extraction spreadsheets. Discrepancies in data extracted were negotiated until consensus was reached. Data were systematically extracted on study characteristics (year, country, study design); study participants (occupation, number of participants); intervention (content, duration); implementation approaches and evaluation (details on methods of implementation, evaluation methods applied, main findings); and barriers and facilitators (methods of data extraction, factors or themes of either enhancing or hampering effect on implementation). In qualitative studies, barriers and facilitators were extracted in their original format, unless the authors had coded the factors to specific themes indicating otherwise. In quantitative studies, factors were extracted if $50 \%$ or more of the participants indicated the factor as a barrier or facilitator. If the authors of the original study did not state the factors as barriers or facilitators, the reviewers would assess the influence on the implementation, as either enhancing/positive (facilitator) or hampering/negative (barrier).

\section{Sorting the data using the theoretical domains framework}

To further organize and make sense of the data, we used TDF to code the extracted barriers and facilitators into domains. TDF contains 14 domains, which offers a theoretical perspective on the cognitive, affective, social, and environmental influences on behaviour [24, 30].

A coding manual (Additional file 2) was developed to guide the coding process [23, 30,31]. Two coders (AGD and $\mathrm{SM}$ ) independently coded barriers and facilitators. Barriers and facilitators could be coded to more than one domain if deemed relevant. Any disputes about the meaning of domain definitions or coding of factors were resolved by discussion until agreement was reached. 
Table 1 Inclusion and exclusion criteria

\begin{tabular}{|c|c|}
\hline Inclusion criteria & Exclusion criteria \\
\hline Participants: age $18+$, employed & Participants: age under 18, unemployed \\
\hline Content: & Content: \\
\hline Intervention: Implementation of physical activity at workplaces: & Intervention: Implementation of other kinds of "Employee health": \\
\hline Physical training & Ergonomics \\
\hline Physical exercises & Active transport to/from work \\
\hline Exercise & Promotion of health, e.g., via e-mail \\
\hline "Active breaks" & Diet \\
\hline Flexibility and mobility exercises & Smoking \\
\hline Outcome: & Alcohol \\
\hline \multirow{7}{*}{$\begin{array}{l}\text { Any kind of evaluation of the implementation process. Qualitative, } \\
\text { quantitative, or mixed methods }\end{array}$} & Psychological work environment \\
\hline & "Return-to-work" interventions \\
\hline & "Sickness absence management" \\
\hline & Occupational safety \\
\hline & Walking/walking on stairs \\
\hline & Outcome: \\
\hline & No evaluation of the implementation process \\
\hline Context: Any kind of workplace & Context: Other than workplaces \\
\hline \multicolumn{2}{|l|}{ Type of publication: All types } \\
\hline \multicolumn{2}{|l|}{ Year of publication: After 2008} \\
\hline Languages: English, Danish, Swedish, Norwegian & \\
\hline
\end{tabular}

The development of the inclusion and exclusion criteria was guided by Joanna Briggs Institute: Reviewer's Manual, chapter 11.2.4 on inclusion criteria in scoping reviews [28]

\section{Data synthesis}

The study population, implementation strategies, evaluative methods and key findings of the included studies were descriptively summarised and presented. The results of the TDF coding process were summarised for each domain, and the absolute number and proportion of codes was calculated for the barriers and facilitators respectively. Lastly, the main themes from the coding process were identified and examples from identified barriers and facilitators were presented to illustrate the coding process.

\section{Results}

\section{Study selection}

We identified a total of 8,715 citations. From these, 2, 455 citations were excluded as duplicates and 3,846 citations were excluded due to publication date or language. A total of 2,414 titles and abstracts were screened, which resulted in screening of 50 full-text papers. Nine references met the inclusion criteria [32-40]. Additionally, seven references were identified by searching reference lists of included studies [17, 41-46]. This resulted in a total of 16 included articles concerning eight different studies. The PRISMA flow diagram demonstrating the selection process is illustrated in Fig. 1 [47].

\section{Description of included studies}

Table 2 presents an overview of the included studies. Three of the eight studies were undertaken in the United States [32-34, 39], three in Denmark [35, 38, 40], and two in the United Kingdom [36, 37]. The studies were published between 2013 and 2018. Four studies were qualitative [32, 33, 36, 39, 40], one study was quantitative [38], and three studies were mixed-methods [34, 35, 37]. The reports included a total of 2,686 participants with a range of 41-1,260 participants per study.

\section{Study population}

Five out of eight studies included office workers and/ or white-collar workers with mostly sedentary work [32-35, 38, 40]. One study included university employees [36], and one study included participants from five different companies (bus company, hospital, university, city council, and government agency) [37]. One study focused on employees who did not meet the recommendations for physical activity [36], and one study included employees who were experiencing pain in the neck and shoulders [40]. Only one study focused on an occupation with high physical work demands (firefighters) [39]. 


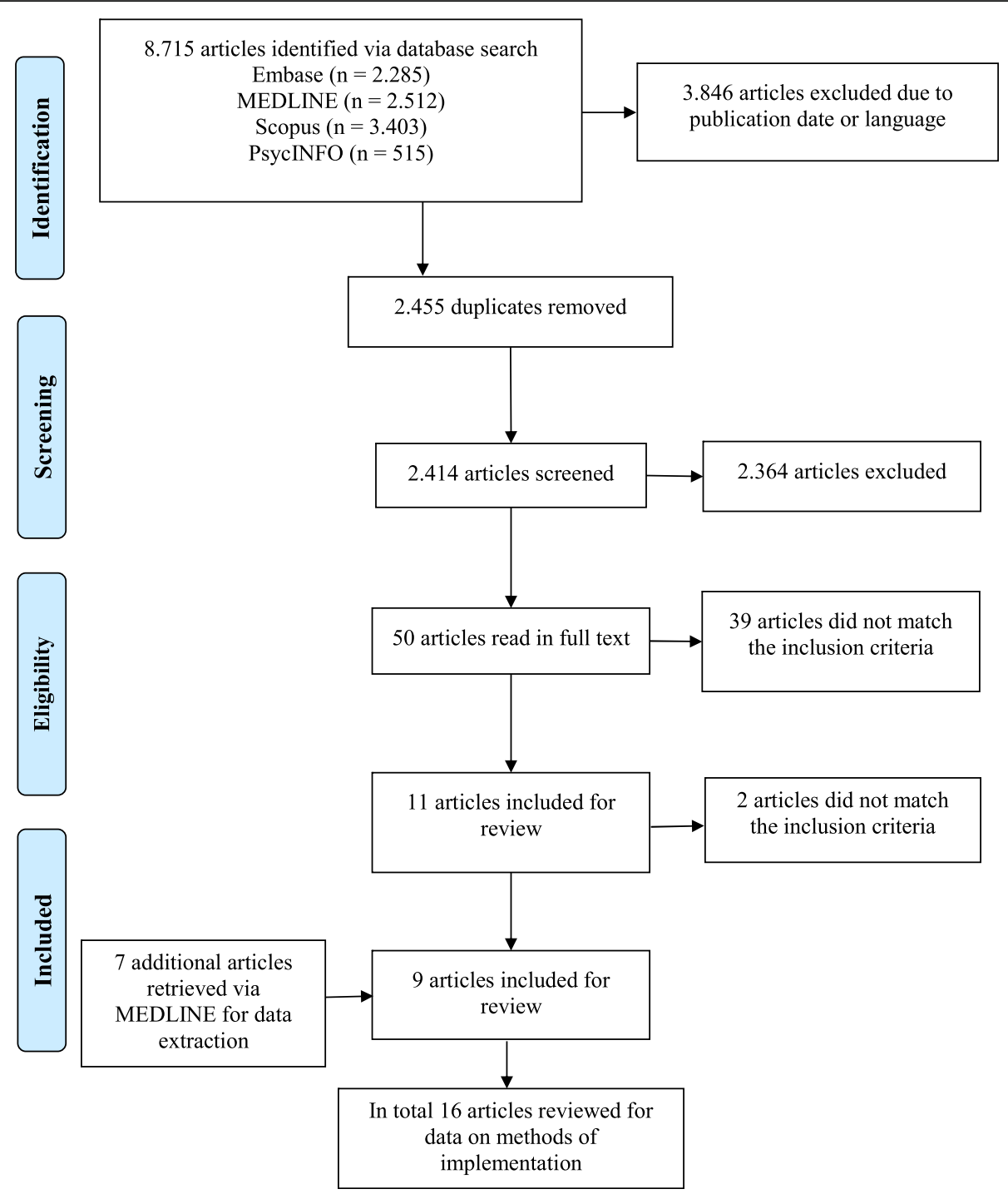

Fig. 1 PRISMA Flowchart

\section{Interventions}

In five out of eight included studies the physical activity intervention was comprised by cardio [32, 33, 35], strength [32, 33, 35, 38-40] or functional exercises [35]. The remaining three interventions encompassed treadmill workstations [34], an indoor bicycle HIIT program [36] and a motivating toolkit and team challenges [37]. Three interventions were group-based [32, 33, 36, 37] and five focussed on the individual [34, 35, 38-40]. The interventions either took place at the worksite [32, 33, $38,39]$, near the worksite [36] or both [35, 37, 40]. The duration of the interventions spanned from 10 weeks to 2 years and incorporated different time schedules. E.g. Taylor et al. applied exercises $15 \mathrm{~min}$ a day, one study applied indoor bicycle HIIT for 18-25 min, three times a week [36] and another scheduled exercise for 1 hour a week [35]. Also, different methods of instruction were applied across the interventions, differing from trained participants being in charge of instruction [32, 33], to professional instructors overseeing some [35, 38, 40] or all training sessions [36, 39].

\section{Methods of evaluation}

Five out of eight included studies applied more than one method of evaluating the implementation process [3438]. The most commonly applied methods were focus group interviews $(n=5)$ [34-37, 39] and surveys $(\mathrm{n}=5)$ [33-35, 37, 38]. Individual interviews were used in three studies [32, 35, 40], fieldnotes in three studies [35-37], and one study used training diaries to evaluate implementation [38]. Six out of eight studies evaluated the implementation from the employees' perspectives only [32-34, 36-38, 40], and two studies evaluated from the managers' and employees' perspectives [35, 39]. 
Table 2 Overview of included studies and articles

\begin{tabular}{|c|c|c|c|c|c|c|c|c|}
\hline \# & $\begin{array}{l}\text { Authors, } \\
\text { year, } \\
\text { country }\end{array}$ & Design & Participants & Intervention & $\begin{array}{l}\text { Methods of } \\
\text { implementation }\end{array}$ & $\begin{array}{l}\text { Methods of } \\
\text { evaluation }\end{array}$ & $\begin{array}{l}\text { Authors' main } \\
\text { conclusions }\end{array}$ & Comments \\
\hline \#1 & $\begin{array}{l}\text { Taylor et } \\
\text { al. 2013, } \\
\text { USA } \\
\text { Taylor et } \\
\text { al. 2014, } \\
\text { USA } \\
\text { Taylor et } \\
\text { al. 2010, } \\
\text { USA }\end{array}$ & $\begin{array}{l}\text { Qualitative } \\
\text { and } \\
\text { quantitative }\end{array}$ & $\begin{array}{l}\text { Office and } \\
\text { hospital } \\
\text { employees } \\
(n=82)\end{array}$ & $\begin{array}{l}\text { Booster breaks. } \\
\text { Cardio, strength, } \\
\text { relaxation exercises } \\
\text { in groups of } 5-15 \\
\text { participants. } 15 \text { min. } \\
\text { Per day for } 6 \text { or } 12 \\
\text { months. In lunch or } \\
\text { conference rooms } \\
\text { at } 5 \text { worksites. }\end{array}$ & $\begin{array}{l}\text { Kick-off event, } \\
\text { "ambassadors" } \\
\text { partnership (Break } \\
\text { Buddies), prizes } \\
\text { and economic } \\
\text { incentives, definite } \\
\text { schedule for } \\
\text { exercise sessions, } \\
\text { hand out manuals. }\end{array}$ & $\begin{array}{l}\text { Interviews with } 24 \\
\text { participants. } \\
\text { Survey: Three } \\
\text { open-ended ques- } \\
\text { tions on the inter- } \\
\text { ventions effect on } \\
\text { the lives of the par- } \\
\text { ticipants and sug- } \\
\text { gestions for } \\
\text { improvements and } \\
\text { a story path } \\
\text { method - before, } \\
\text { during, after the } \\
\text { intervention }\end{array}$ & $\begin{array}{l}\text { Advantages: } \\
\text { Positive feelings } \\
\text { and reduced stress, } \\
\text { enhanced focus on } \\
\text { health, } \\
\text { strengthened social } \\
\text { interactions and } \\
\text { organisational } \\
\text { support. } \\
\text { Barriers: Lack of } \\
\text { time, motivation } \\
\text { and social/ } \\
\text { organisational } \\
\text { support and no } \\
\text { variation in the } \\
\text { training }\end{array}$ & $\begin{array}{l}\text { Only the most } \\
\text { frequently } \\
\text { occurring } \\
\text { themes are } \\
\text { mentioned }\end{array}$ \\
\hline \#2 & $\begin{array}{l}\text { Tudor- } \\
\text { Locke et } \\
\text { al. } 2014 \text {, } \\
\text { USA }\end{array}$ & $\begin{array}{l}\text { Mixed } \\
\text { methods }\end{array}$ & $\begin{array}{l}\text { Office } \\
\text { employees } \\
(n=41)\end{array}$ & $\begin{array}{l}\text { The WorkStation } \\
\text { Pilot Study. } \\
\text { Treadmill } \\
\text { workstations. } \\
\text { Individually, } \\
\text { scheduled rotation } \\
\text { among } \\
\text { workstations. Two } \\
\text { daily sessions of } 45 \\
\text { min. For } 6 \text { months }\end{array}$ & $\begin{array}{l}\text { Kick-off event, } \\
\text { prizes and } \\
\text { economic } \\
\text { incentives, follow- } \\
\text { up from the re- } \\
\text { search team, op- } \\
\text { tional support via } \\
\text { phone or email }\end{array}$ & $\begin{array}{l}\text { Web-based, post- } \\
\text { session surveys and } \\
\text { focus group } \\
\text { interviews }\end{array}$ & $\begin{array}{l}\text { Most common } \\
\text { reasons for absence } \\
\text { were conflict with } \\
\text { work tasks, not in } \\
\text { the office or } \\
\text { sickness absence. } \\
\text { Most of the } \\
\text { participants were } \\
\text { positive toward } \\
\text { treadmill } \\
\text { workstations. }\end{array}$ & $\begin{array}{l}\text { Very low } \\
\text { participation } \\
\text { rate. } 17 \% \\
\text { responded to } \\
\text { recruitment. } \\
5.6 \% \text { attended } \\
\text { baseline. }\end{array}$ \\
\hline \#3 & $\begin{array}{l}\text { Justesen } \\
\text { et al. 2017, } \\
\text { DK } \\
\text { Sjøgaard } \\
\text { et al. 2014, } \\
\text { DK }\end{array}$ & $\begin{array}{l}\text { Mixed } \\
\text { methods }\end{array}$ & $\begin{array}{l}\text { Office } \\
\text { employees } \\
(n=389)\end{array}$ & $\begin{array}{l}\text { IPET }^{\text {a }} \text {-Individually } \\
\text { tailored cardio, } \\
\text { strength, functional } \\
\text { exercise. } 1 \mathrm{~h} \text { per } \\
\text { week for } 2 \text { years. At } \\
\text { worksites or in the } \\
\text { local area. }\end{array}$ & $\begin{array}{l}\text { Information } \\
\text { meetings for the } \\
\text { participants, } \\
\text { "change agents", } \\
\text { instructors/ } \\
\text { supervision, } \\
\text { handout manuals, } \\
\text { individually } \\
\text { adjusted training, } \\
\text { log books/training } \\
\text { journals }\end{array}$ & $\begin{array}{l}\text { Survey questions } \\
\text { for all employees, } \\
\text { fieldnotes from } \\
\text { meetings with } \\
\text { change agents, } \\
\text { survey and focus } \\
\text { group interview } \\
\text { with change } \\
\text { agents, and survey } \\
\text { and interview with } \\
\text { middle } \\
\text { management }\end{array}$ & $\begin{array}{l}\text { Middle } \\
\text { management plays } \\
\text { a major role in the } \\
\text { implementation of } \\
\text { physical exercise. } \\
\text { But they are often } \\
\text { unsure about this } \\
\text { role and tend to } \\
\text { leave all } \\
\text { responsibility to the } \\
\text { top management }\end{array}$ & $\begin{array}{l}\text { Only the middle } \\
\text { manager's role } \\
\text { in the } \\
\text { implementation } \\
\text { process is } \\
\text { evaluated. }\end{array}$ \\
\hline$\# 4$ & $\begin{array}{l}\text { Kinnafik et } \\
\text { al. 2018, } \\
\text { UK } \\
\text { Shepherd } \\
\text { et al. 2015, } \\
\text { UK }\end{array}$ & $\begin{array}{l}\text { Qualitative } \\
\text { and } \\
\text { quantitative }\end{array}$ & $\begin{array}{l}\text { University } \\
\text { employees } \\
(n=46)\end{array}$ & $\begin{array}{l}\text { Indoor bicycles HIIT } \\
\text { b program. In } \\
\text { groups. 18-25 min. } \\
3 \text { times per week } \\
\text { for } 10 \text { weeks. In } \\
\text { close proximity to } \\
\text { the worksite. }\end{array}$ & $\begin{array}{l}\text { Information } \\
\text { meetings for the } \\
\text { participants, flexible } \\
\text { schedule for } \\
\text { exercise sessions, } \\
\text { instructors/ } \\
\text { supervision, } \\
\text { individually } \\
\text { adjusted training }\end{array}$ & $\begin{array}{l}\text { Focus group } \\
\text { interviews guided } \\
\text { by the RE-AIM } \\
\text { framework and ob- } \\
\text { servation notes } \\
\text { from focus group } \\
\text { interviews }\end{array}$ & $\begin{array}{l}\text { HIIT is an } \\
\text { acceptable and } \\
\text { efficient method of } \\
\text { exercise for } \\
\text { employees who are } \\
\text { insufficiently } \\
\text { physically active. } \\
\text { Social factors } \\
\text { influenced the level } \\
\text { of adherence. } \\
\text { Despite this, } \\
\text { participants were } \\
\text { reluctant to } \\
\text { continue with the } \\
\text { HIIT training. }\end{array}$ & $\begin{array}{l}12 \text { participants } \\
\text { in the } \\
\text { evaluation }\end{array}$ \\
\hline$\# 5$ & $\begin{array}{l}\text { Lawton et } \\
\text { al. 2014, } \\
\text { UK } \\
\text { McEachan } \\
\text { et al. 2011, } \\
\text { UK }\end{array}$ & $\begin{array}{l}\text { Mixed } \\
\text { methods }\end{array}$ & $\begin{array}{l}\text { Employees at } \\
\text { a bus } \\
\text { company, } \\
\text { hospital, } \\
\text { university, } \\
\text { city council, } \\
\text { and } \\
\text { government } \\
\text { agency ( } n= \\
\text { 1260) }\end{array}$ & $\begin{array}{l}\text { "AME for Activity" } \\
\text { (Awareness, } \\
\text { Motivation, } \\
\text { Environment). A } \\
\text { toolkit of activities } \\
\text { to increase physical } \\
\text { activity. Team } \\
\text { based. } 3 \text { months. } 44 \\
\text { worksites. }\end{array}$ & $\begin{array}{l}\text { Kick-off event, } \\
\text { "ambassadors" } \\
\text { focus on visual } \\
\text { design, flexible } \\
\text { schedule for } \\
\text { exercise sessions, } \\
\text { hand out manuals, } \\
\text { follow-up from the } \\
\text { research team }\end{array}$ & $\begin{array}{l}\text { Survey, focus group } \\
\text { interview and } \\
\text { fieldnotes }\end{array}$ & $\begin{array}{l}\text { The intervention is } \\
\text { efficient under ideal } \\
\text { circumstances, } \\
\text { which entail } \\
\text { commitment by } \\
\text { facilitators, } \\
\text { susceptibility and } \\
\text { engagement by } \\
\text { employees, and the } \\
\text { physical }\end{array}$ & \\
\hline
\end{tabular}


Table 2 Overview of included studies and articles (Continued)

\begin{tabular}{|c|c|c|c|c|c|c|c|c|}
\hline \# & $\begin{array}{l}\text { Authors, } \\
\text { year, } \\
\text { country }\end{array}$ & Design & Participants & Intervention & $\begin{array}{l}\text { Methods of } \\
\text { implementation }\end{array}$ & $\begin{array}{l}\text { Methods of } \\
\text { evaluation }\end{array}$ & $\begin{array}{l}\text { Authors' main } \\
\text { conclusions }\end{array}$ & Comments \\
\hline & & & & & & & surroundings & \\
\hline \#6 & $\begin{array}{l}\text { Andersen } \\
\text { \& Zebis } \\
\text { 2014, DK } \\
\text { Andersen } \\
\text { et al. 2011, } \\
\text { DK }\end{array}$ & Quantitative & $\begin{array}{l}\text { Office } \\
\text { employees } \\
(n=198)\end{array}$ & $\begin{array}{l}\text { To reduce } \\
\text { musculoskeletal } \\
\text { disorders. Strength } \\
\text { training with elastic } \\
\text { bands. Individually. } \\
1 \text { exercise for either } \\
2 \text { or } 12 \text { min. Daily } \\
\text { for } 10 \text { weeks. At } \\
\text { office worksites. }\end{array}$ & $\begin{array}{l}\text { Information } \\
\text { meetings for the } \\
\text { participants, } \\
\text { instructors/ } \\
\text { supervision, hand } \\
\text { out manuals, } \\
\text { planned } \\
\text { progression, log } \\
\text { books/ training } \\
\text { journals, optional } \\
\text { support via phone } \\
\text { or email }\end{array}$ & $\begin{array}{l}\text { Definitions of } \\
\text { reach, dose } \\
\text { delivered, dose } \\
\text { received, fidelity } \\
\text { and satisfaction. } \\
\text { Surveys and } \\
\text { training journals }\end{array}$ & $\begin{array}{l}\text { The strength } \\
\text { training was } \\
\text { generally well } \\
\text { accepted by the } \\
\text { participants, but } \\
\text { more variation is } \\
\text { needed. } \\
\text { Lack of time and } \\
\text { difficulties } \\
\text { following illness } \\
\text { were the greatest } \\
\text { barriers }\end{array}$ & $\begin{array}{l}116 \text { participants } \\
\text { in the } \\
\text { evaluation }\end{array}$ \\
\hline \#7 & $\begin{array}{l}\text { Mayer et } \\
\text { al. 2013, } \\
\text { USA } \\
\text { Mayer et } \\
\text { al. 2013, } \\
\text { USA }\end{array}$ & $\begin{array}{l}\text { Qualitative } \\
\text { and } \\
\text { quantitative }\end{array}$ & $\begin{array}{l}\text { Firefighters, } \\
\text { fulltime }(n= \\
94)\end{array}$ & $\begin{array}{l}\text { Supervised exercise. } \\
\text { Strengthening of } \\
\text { back and core } \\
\text { muscles. } 2 \text { sessions } \\
\text { of } 10-15 \text { min. Per } \\
\text { week for } 24 \text { weeks. } \\
\text { At fire stations. }\end{array}$ & $\begin{array}{l}\text { Flexible schedule } \\
\text { for exercise } \\
\text { sessions, } \\
\text { instructors/ } \\
\text { supervision, } \\
\text { planned } \\
\text { progression }\end{array}$ & $\begin{array}{l}\text { Focus group } \\
\text { interviews. Three } \\
\text { with employees } \\
\text { and one with } \\
\text { leaders. Eight } \\
\text { open-ended } \\
\text { questions }\end{array}$ & $\begin{array}{l}\text { Lack of self- } \\
\text { motivation, support } \\
\text { from colleagues } \\
\text { and time during } \\
\text { the workday were } \\
\text { the greatest } \\
\text { barriers }\end{array}$ & $\begin{array}{l}27 \text { participants } \\
\text { in the } \\
\text { evaluation }\end{array}$ \\
\hline \#8 & $\begin{array}{l}\text { Bredahl et } \\
\text { al. 2014, } \\
\text { DK } \\
\text { Andersen } \\
\text { et al. 2010, } \\
\text { DK }\end{array}$ & Qualitative & $\begin{array}{l}\text { Office } \\
\text { employees } \\
(n=573)\end{array}$ & $\begin{array}{l}\text { VIMS }{ }^{\complement} \text {. Five } \\
\text { strength training } \\
\text { exercises with } \\
\text { dumbbells for } \\
\text { shoulders, neck and } \\
\text { arms. } 1 \text { h per week } \\
\text { for } 20 \text { weeks. At the } \\
\text { worksites or in the } \\
\text { local area. }\end{array}$ & $\begin{array}{l}\text { Group exercise to } \\
\text { enhance social } \\
\text { relationships, focus } \\
\text { on visual design, } \\
\text { definite schedule } \\
\text { for exercise } \\
\text { sessions, } \\
\text { instructors/ } \\
\text { supervision, } \\
\text { planned } \\
\text { progression, log } \\
\text { books/ training } \\
\text { journals, optional } \\
\text { support via phone } \\
\text { or email }\end{array}$ & $\begin{array}{l}\text { Semi-deductive, } \\
\text { structured } \\
\text { thematical } \\
\text { interviews. Three } \\
\text { themes: } \\
\text { organisation, } \\
\text { implementation, } \\
\text { and individual }\end{array}$ & $\begin{array}{l}\text { The greatest barrier } \\
\text { for participation } \\
\text { was the internal } \\
\text { working culture. A } \\
\text { clear connection } \\
\text { between } \\
\text { management's } \\
\text { intentions and an } \\
\text { actual } \\
\text { implementation is } \\
\text { crucial. } \\
\text { Furthermore, it is } \\
\text { important to } \\
\text { structure the } \\
\text { intervention and } \\
\text { secure flexibility } \\
\text { during the working } \\
\text { hours, to enable } \\
\text { employees to } \\
\text { participate. }\end{array}$ & $\begin{array}{l}18 \text { participants } \\
\text { in the } \\
\text { evaluation }\end{array}$ \\
\hline
\end{tabular}

IPET Intelligent Physical Exercise Training, ${ }^{\mathrm{b}}$ HIIT High Intensity Interval Training, ${ }^{\mathrm{c}}$ VIMS company adjusted intelligent exercise for pain in neck and shoulders

Implementation strategies and facilitation of intervention delivery

The interventions were initiated by information meetings for the participants in three studies [17, 38, 42, 44], and by a kick-off event in three other studies [34, 41, 43]. Three studies used handpicked employees, who were given between one and three days of instruction, as "change agents" or "ambassadors" to facilitate implementation [17, 35, 37, 41, 43]. Other methods of implementations were group exercise to enhance social relationships [46], and partnership through signed declarations of support (Break Buddies) [41]. Two studies offered prizes and economic incentives for participation in the intervention $[34,41]$. Only two studies described the visual design of the intervention with regards to information material, logos, and posters [43, 46]. Bredahl et al., 2015, described a focus on the physical surroundings, in terms of light and friendly training environment and colourful posters on the walls showing the training exercises [46].

\section{Theoretical domains framework - barriers and facilitators}

A total of 109 factors were identified in the eight included studies and were divided between 57 barriers and 52 facilitators. When applying the TDF, the 109 factors were given 181 codes: 94 codes to the barriers and 87 codes to the facilitators. Thus, 53 factors were given codes from more than one TDF domain. Table 3 presents the overall results of the TDF coding. For each study, the number of identified barriers ranged from two to 12 , and for facilitators from three to nine. The barriers were coded under 11 of the 14 TDF domains and most frequently, to the TDF domains Environmental Context and Resources (ECR, $n=34,36.2 \%)$, Social influences $(n=13,13.8 \%)$, and Social/Professional Role and 
Table 3 Overall results of the TDF coding process

\begin{tabular}{|c|c|c|c|c|c|}
\hline \multicolumn{3}{|l|}{ TDF Barriers $(n=94)$} & \multicolumn{3}{|l|}{ TDF Facilitators $(n=87)$} \\
\hline Domain & (n) & (\%) & Domain & (n) & (\%) \\
\hline$\overline{E C R}$ & 34 & $36.2 \%$ & Social influences & 17 & $19.5 \%$ \\
\hline Social influences & 13 & $13.8 \%$ & $E C R$ & 16 & $18.4 \%$ \\
\hline SPRI & 8 & $8.5 \%$ & SPRI & 9 & $10.3 \%$ \\
\hline Skills & 7 & $7.4 \%$ & Beliefs about capabilities & 8 & $9.2 \%$ \\
\hline Beliefs about consequences & 7 & $7.4 \%$ & Goals & 8 & $9.2 \%$ \\
\hline Intentions & 7 & $7.4 \%$ & Knowledge & 6 & $6.9 \%$ \\
\hline Beliefs about capabilities & 6 & $6.4 \%$ & Emotion & 6 & $6.9 \%$ \\
\hline Emotion & 5 & $5.3 \%$ & Behavioural regulation & 5 & $5.7 \%$ \\
\hline Knowledge & 4 & $4.3 \%$ & Skills & 4 & $4.6 \%$ \\
\hline Goals & 1 & $1.1 \%$ & Intentions & 3 & $3.4 \%$ \\
\hline Behavioural regulation & 2 & $2.1 \%$ & Reinforcement & 2 & $2.3 \%$ \\
\hline Optimism & 0 & $0 \%$ & Beliefs about consequences & 1 & $1.1 \%$ \\
\hline Reinforcement & 0 & $0 \%$ & Optimism & 1 & $1.1 \%$ \\
\hline MADP & 0 & $0 \%$ & MADP & 1 & $1.1 \%$ \\
\hline
\end{tabular}

TDF Theoretical Domains Framework, SPRI Social/professional role and Identity, ECR Environmental Context and Resources, MADP Memory, Attention and Decision Processes

Identity (SPRI, $n=8,8.5 \%$ ). We did not find barriers relating to the domains Optimism, Reinforcement and Memory, Attention and Decision Processes. Likewise, the facilitators were most frequently coded to the TDF domains Social influences ( $n=17,19.5 \%)$, Environmental Context and Resources (ECR, $n=16,18.4 \%$ ), and Social/ Professional Role and Identity (SPRI, $n=9,10.3 \%$ ). The facilitators covered all 14 TDF domains. For an overview of the TDF coding, see Additional file 3.

Barriers and facilitators coded to the ECR domain covered organisational culture and resources and employees' interactions with, and influences of, the surrounding environment. Under the ECR domain, all eight studies identified lack of time, conflicting work time schedules, or alternating workstations/work locations as barriers [32, 34-40]. E.g., in Taylor et al., $48 \%$ of the data texts collected from interviews regarding barriers concerned issues with scheduling the exercise, time constraints, and interruptions of work flow [32]. Further, vacation or sickness absence interrupting the program was perceived as a barrier [34, 37]. Several studies reported suboptimal implementation because of a lack of awareness among employees about the intervention [36, 37] or workstations not suitably equipped for both work and exercise [34]. For example, Tudor-Lock et al. reported how fitting a rigid schedule of shared use of treadmill desks with the equally rigid work schedule was challenging [34]. In addition, the treadmill desks lacked necessary equipment and compromised the confidentiality during telephone calls [34]. Four studies reported that study participants lost motivation because the exercise programs lacked variation [33, 38-40], and in one study, some participants were disinclined to engage in workplace-based exercise, as they felt this activity belonged to leisure time and private life rather than work life [35]. Other barriers coded under the ECR domain were disturbing noises from workstation treadmills [34] and increased room temperature as a result of exercising [36].

Facilitators under the ECR codes related to the positive evaluations of the content of the exercise programs with respect to intensity and frequency of the exercises [36, 38], the simplicity of the program [39], and the flexibility of the programs in terms of location, time spent on exercising, and timing during the workday [36, 40]. In two studies, the opportunity to meet and spend time with colleagues was mentioned as a facilitating factor [37, 40]. Further, structured breaks [32], change agents [35], the work team working in the same location [37], and clear distribution of roles and responsibilities between project implementers and management [35] were reported as facilitating.

Factors that impact uptake of the interventions and coded to the Social influences domain covered interpersonal processes, social support and norms, group conformity and identity, and intergroup conflict. Three studies reported lack of managerial support [32, 33, 35, 37], and four studies reported lack of social/collegial support as factors which impede uptake $[32,36,39,40]$. For example, lack of camaraderie amongst colleagues was reported as a barrier by Taylor et al. [32], and in Mayer et al., participants reported that they would have been more motivated by group-based exercise than the implemented individual exercise [39]. Bredahl et al. reported that doing exercise and sweating in a public place was perceived as a barrier for some participants. In the same study, colleagues were found to hinder PA if they were pressuring others to keep working instead of doing exercise [40]. Other barriers 
under the Social influences domain were lack of motivation/ commitment [32, 37] and instructors without appropriate competences and/or behaviour [36, 40].

Just as the lack of social/collegial support was found to impede PA, the presence of this support was reported to facilitate workplace PA [36-40]. Building a sense of team spirit or camaraderie amongst colleagues and doing activities together with colleagues were reported as means to create this support $[36,39,40]$. Further, supervision of the exercise by instructors [36, 38, 39] and support, acknowledgement, and active participation from management facilitated uptake $[32,35,37,40]$.

Factors coded to the SPRI domain covered behaviours and personal qualities, professional, social and group identity, and organisational commitment and leadership. Barriers coded to SPRI related to inconsistent or lack of support from management [33, $35,37]$. Lawton et al. reported that despite being supportive at the beginning, management would not allow employees the time and resources needed for the intervention [37]. In Taylor et al., participants suggested that management should participate more in the exercise sessions and be more encouraging [33]. Further, lack of project management and unclear roles between implementers/project managers and workplace managers impeded uptake [35].

The SPRI facilitators included sense of acceptance and legitimacy of participation as a result of managerial awareness, attitude and support [33, 35, 37, 40]. Other facilitators included team spirit and improved social work atmosphere [32].

Together, the ECR, Social influences and SPRI codes make up $58.5 \%$ of the coded barriers and $48.2 \%$ of the coded facilitators. The remaining $41.5 \%$ of the barriers are divided between eight domains, with the domains Skills, Beliefs about consequences, Intentions and Beliefs about capabilities with the highest representation. For the barriers, these domains cover lack of knowledge regarding health promotion, the intervention being too difficult or too easy [34, 35, 39], a sense of interference with one's private life, the timing of the intervention $[35,37,39]$, prioritisation of tasks, lack of commitment $[35,37]$, difficulties in the execution of the intervention, or loss of motivation in the event of negative results $[34,36]$. The remaining $51.8 \%$ of the facilitators are divided between the remaining 11 domains, with the domains Beliefs about capabilities, and Goals, Knowledge and Emotions being the most prevalent. Acting as facilitating factors were feelings of enhanced competence and selfconfidence [36, 39], or motivation to behaviour change and exercise [33, 40], increased health [32, 34, $39]$, and decreased pain $[39,40]$, or the experience of positive feelings towards, and greater joy with, physical activity [32, 34, 36].

\section{Discussion \\ Principal findings}

We have systematically searched and descriptively summarized the literature pertaining to implementation approaches of workplace-based PA interventions, and the barriers and facilitators affecting uptake of such interventions. We found a large degree of variety regarding intervention content, delivery, and implementation; thereby, making comparisons between interventions difficult. We applied TDF to organise and describe barriers and facilitators, and found factors related to all 14 TDF domains, which underpins the multilevel dimensions and complexity of implementation of workplace-based PA interventions.

The majority of factors affecting uptake of workplacebased PA were coded to three TDF domains, ECR, Social influences, and SPRI. In most cases, we consistently found that absence of these factors hindered uptake, whereas presence facilitated uptake of the intervention. This indicates that focus and action must be directed toward these factors, otherwise they will hinder the uptake when implementing PA in workplaces. We found both intrinsic factors in the individual participants, like unwillingness to participate in workplace PA as this was believed to infringe on private matters, or participants feeling exposed when exercising in front of colleagues, and extrinsic factors related to different levels in the organisation and the persons acting within the organisation. These included organisation of work task and work schedules, prioritisation and allocation of resources, managerial support and commitment, and the importance of social coherence and group dynamics. The content, flexibility, variation of the intervention and competency of those delivering the intervention also impact uptake.

\section{Factors affecting uptake of workplace-based PA}

We found that a variety of methods have been applied in the implementation of workplace-based PA interventions, but in general, the engagement strategies used were not described in detail. Information meetings, kickoff events, and the application of handpicked, educated employees as "change agents" or "ambassadors" were the most common methods of implementation. The concept of "change agents" is advocated by several theories and models of behaviour change and implementation, and is based on the theory that any process of change needs someone to take the lead $[48,49]$. "Change agents" have been found useful in diverse settings and conditions, such as prevention and health promotion programs among children [50]; weight management in adults with intellectual disabilities [51]; application of ergonomics among industrial workers [52]; and resident-oriented 
care in nursing homes [53]. We found that individually tailored interventions, adaptability, and flexibility in intervention programs increase uptake. This finding is supported by reviews of both workplace-based health programs [16], and in implementation studies from a wide range of health conditions and situations [50]. Other authors have advocated for short rather than long exercise programs [15]. Further, in concordance with other workplace-based health programs, which have shown that various incentives (e.g., gifts and gift vouchers) improve participation and intervention adherence [16], we found that offering financial incentives increases uptake. Also in line with our results, several other studies stress the importance of leadership support, a collective sense of ownership, allowing employees to take part in the development, a supportive workplace culture, and focus on economic advantages, when implementing health promoting interventions [16, 20, 50,54]. Identifying which engagement and recruitment strategies are most effective for different groups of workers would be beneficial. Conceptual frameworks and metrics have been developed in other areas of health research to help determine which approaches are most successful $[55,56]$. It will be important that future studies describe engagement or recruitment strategies in greater detail to improve the fidelity and impact of these approaches using resources and guides like the template for intervention description and replication (TIDieR) checklist $[56,57]$.

The majority of identified barriers and facilitators were coded to the TDF domains ECR, Social influences, and SPRI. This mirrors, to some extent, the results of other studies, which likewise found ECR and Social influences to be of greatest influence when implementing PA. This has been seen in implementation of PA in school settings [31, 58], and in mental and physical rehabilitation settings [59-61]. Some factors (e.g., interaction with colleagues) were perceived differently among participants, and thus reported as both a barrier and a facilitator. This was observed both within studies and across studies, which further emphasizes the complexity of implementing PA and the importance of attention to individuality and context when designing interventions. Nearly all the included studies exclusively examined company employees' perspectives on barriers and facilitators for implementation of workplace-based PA. Since successful implementation processes of health promoting interventions seem to rely on leadership support and a collective contribution [16, 20,54], research of factors influencing other stakeholders, e.g., management or intervention deliverers could add to the understanding of success or failure of implementation efforts.

\section{Strengths and limitations}

This scoping review was designed and reported in line with the recommendations of the PRISMA-ScR statement [26].
We searched multiple databases, and a thorough search strategy was designed iteratively by the research team, and an information specialist, to account for the three different dimensions of the search (implementation, physical activity, and workplaces). All aspects of data collection, data extraction, and data analysis were carried out independently by two researchers, with a third party available for mediation in case of disagreements. We applied TDF to provide a structured and systematic foundation on which implementers may base the design of future interventions [62]. The application of TDF provides a theoretical foundation for working with implementation and factors affecting uptake, and gives a comprehensive investigation of potential factors relating to implementational difficulties [23]. The primary limitation of this scoping review is the sparse literature related to our objectives. Due to the limited number and type of study designs of the original studies, and the purpose of our review, we were not able to elucidate any relationship between factors that impact uptake of physical activity and the population or the content of the intervention.

Additionally, our search was limited to studies published from 2009 and onwards, and in English, Danish, Swedish, or Norwegian. The restrictions in language could be taken as a limitation, although there is some indication that this has only marginal impact on results [63], and grey literature was not included. We did not assess the quality of the included studies, as this is usually not part of a scoping review, due to an effort to keep a wide perspective and include studies with different methods and designs [29].

\section{Future research and practical application}

We have found many different factors affecting the success of implementation of workplace-based PA interventions, which highlight the need for well-planned implementation processes considering multiple levels and factors. In workplace-based PA studies, only few have undertaken process evaluations and even fewer base these on a theoretical framework [64]. This is a well-known challenge in implementation science, and studies addressing these issues, have been sought by researchers in the fields of implementation and health promotion [21, 22, 64]. Future research should focus on the application of theoretically informed process evaluations including all stakeholders, to provide standardised information on successful and unsuccessful implementation methods. We recommend implementers of workplace-based PA to apply a systematic approach, which ensures consideration of all influencing factors. Incorporation of a thorough assessment of needs and available resources and involvement of all participating parties would likely assist the process positively. Using implementation frameworks, like TDF, the linking of theories of behaviour change to behaviour change techniques and approaches becomes more tangible and relevant [30], thus 
enabling a better connection between intervention functions and behaviour change techniques to further guide intervention design [65].

\section{Conclusions}

Our review has highlighted the multilevel factors affecting the uptake of workplace-based PA and it underpins the complexities in implementation of such initiatives. The published literature predominantly provides details from the employees' perspectives on factors that need to be addressed, and a lack of attention to these factors could cause them to hamper uptake of PA. The analysis of barriers and facilitators provides a theoretical foundation to guide future intervention design. However, it is clear that further research is needed to fully understand the success or failure of implementation processes.

\section{Additional files}

Additional file 1: Search matrices and protocols. Search matrix + protocol for each of the four databases. (DOCX $21 \mathrm{~kb}$ )

Additional file 2: TDF coding manual. TDF domains, definitions and constructs used to code barriers and facilitators. (DOCX $18 \mathrm{~kb}$ )

Additional file 3: Overview of the TDF coding. Total number of identified factors and results of TDF coding for the included studies. (DOCX $17 \mathrm{~kb}$ )

\section{Abbreviations}

ECR: Environmental Context and Resources; HIIT: High Intensity Interval Training; IPET: Intelligent Physical Exercise Training; MADP: Memory, Attention, and Decision Processes; MeSH: Medical Subject Headings; PA: Physical activity; PRISMA: Preferred Reporting Items for Systematic reviews and Meta-Analysis; PRISMA-ScR: Preferred Reporting Items for Systematic reviews and Meta-Analysis extension for Scoping Reviews; RCT: Randomised controlled trial; SPRI: Social/Professional Role and Identity; TDF: Theoretical Domains Framework

\section{Acknowledgements}

Not applicable.

\section{Authors' contributions}

AGD, SM, TVGB, and MJS contributed to the concept and design of the study, which was led by AGD. AGD, SM, and MJS developed the search strategy, and AGD performed the literature search. AGD and SM performed the study selection, extraction, and analysis of data. AGD drafted the first version of the manuscript, and all authors critically revised the manuscript for important intellectual content and gave final approval of the version to be published.

\section{Authors' information}

Not applicable

\section{Funding}

This study was funded by in kind contributions from the authors' institutions. The funding bodies had no role in the design of the study; collection, analysis, and interpretation of data; in writing of the manuscript; or in the decision to submit the article for publication.

\section{Availability of data and materials}

All data generated or analysed during this study are included in this published article [and its supplementary information files].
Consent for publication

Not applicable.

\section{Competing interests}

This article was commissioned and peer reviewed. MJS is a society representative of Chiropractic and Manual Therapies but had no influence over the review assignment or process. The authors declare that they have no further competing interests.

Received: 11 December 2018 Accepted: 5 July 2019

Published online: 09 October 2019

\section{References}

1. Church TS, Thomas DM, Tudor-Locke C, Katzmarzyk PT, Earnest CP, Rodarte $R Q$, et al. Trends over 5 decades in U.S. occupation-related physical activity and their associations with obesity. PLoS One. 2011;6(5):e19657.

2. de Rezende LF, Rodrigues Lopes M, Rey-Lopez JP, Matsudo VK, Luiz OC. Sedentary behavior and health outcomes: an overview of systematic reviews. PLoS One. 2014;9(8):e105620.

3. Straker L, Mathiassen SE. Increased physical work loads in modern work--a necessity for better health and performance? Ergonomics. 2009;52(10):1215-25.

4. Lidegaard M, Sogaard K, Krustrup P, Holtermann A, Korshoj M. Effects of 12 months aerobic exercise intervention on work ability, need for recovery, productivity and rating of exertion among cleaners: a worksite RCT. Int Arch Occup Environ Health. 2018;91(2):225-35.

5. Sjogaard G, Christensen JR, Justesen JB, Murray M, Dalager T, Fredslund GH, et al. Exercise is more than medicine: the working age population's wellbeing and productivity. J Sport Health Sci. 2016;5(2):159-65.

6. Dalager T, Justesen JB, Murray M, Boyle E, Sjogaard G. Implementing intelligent physical exercise training at the workplace: health effects among office workers-a randomized controlled trial. Eur J Appl Physiol. 2016;116(7):1433-42.

7. Dalager T, Bredahl TG, Pedersen MT, Boyle E, Andersen LL, Sjogaard G. Does training frequency and supervision affect compliance, performance and muscular health? A cluster randomized controlled trial. Man Ther. 2015;20(5):657-65.

8. Dalager T, Justesen JB, Sjogaard G. Intelligent physical exercise training in a workplace setting improves muscle strength and musculoskeletal pain: a randomized controlled trial. Biomed Res Int. 2017;2017:7914134.

9. Mortensen P, Larsen Al, Zebis MK, Pedersen MT, Sjogaard G, Andersen LL. Lasting effects of workplace strength training for neck/shoulder/arm pain among laboratory technicians: natural experiment with 3-year follow-up. Biomed Res Int. 2014;2014:845851.

10. Andersen $\mathrm{CH}$, Andersen LL, Gram B, Pedersen MT, Mortensen OS, Zebis MK, et al. Influence of frequency and duration of strength training for effective management of neck and shoulder pain: a randomised controlled trial. $\mathrm{Br} J$ Sports Med. 2012:46(14):1004-10.

11. Zebis MK, Andersen LL, Pedersen MT, Mortensen P, Andersen $\mathrm{CH}$, Pedersen MM, et al. Implementation of neck/shoulder exercises for pain relief among industrial workers: a randomized controlled trial. BMC Musculoskelet Disord. 2011;12:205.

12. Kuoppala J, Lamminpaa A, Husman P. Work health promotion, job wellbeing, and sickness absences--a systematic review and meta-analysis. J Occup Environ Med. 2008;50(11):1216-27.

13. Justesen JB, Sogaard K, Dalager T, Christensen JR, Sjogaard G. The effect of intelligent physical exercise training on sickness Presenteeism and absenteeism among office workers. J Occup Environ Med. 2017;59(10):942-8.

14. Pereira MJ, Coombes BK, Comans TA, Johnston V. The impact of onsite workplace health-enhancing physical activity interventions on worker productivity: a systematic review. Occup Environ Med. 2015;72(6):401-12.

15. White MI, Dionne CE, Warje O, Koehoorn M, Wagner SL, Schultz IZ, et al. Physical activity and exercise interventions in the workplace impacting work outcomes: a stakeholder-centered best evidence synthesis of systematic reviews. Int J Occup Environ Med. 2016;7(2):61-74.

16. Cancelliere C, Cassidy JD, Ammendolia C, Cote P. Are workplace health promotion programs effective at improving presenteeism in workers? A systematic review and best evidence synthesis of the literature. BMC Public Health. 2011;11:395

17. Sjogaard G, Justesen JB, Murray M, Dalager T, Sogaard K. A conceptual model for worksite intelligent physical exercise training--IPET--intervention for decreasing life style health risk indicators among employees: a randomized controlled trial. BMC Public Health. 2014;14:652. 
18. Andersen LL. Influence of psychosocial work environment on adherence to workplace exercise. J Occup Environ Med. 2011;53(2):182-4.

19. Pedersen MM, Zebis MK, Langberg H, Poulsen OM, Mortensen OS, Jensen $\mathrm{JN}$, et al. Influence of self-efficacy on compliance to workplace exercise. Int J Behav Med. 2013;20(3):365-70.

20. Bailey MM, Coller RK, Pollack Porter KM. A qualitative study of facilitators and barriers to implementing worksite policies that support physical activity. BMC Public Health. 2018;18(1):1145.

21. Nilsen P. Making sense of implementation theories, models and frameworks. Implement Sci. 2015;10:53.

22. Rothman AJ. "Is there nothing more practical than a good theory?": Why innovations and advances in health behavior change will arise if interventions are used to test and refine theory. Int J Behav Nutr Phys Act. 2004;1(1):11.

23. Atkins $L$, Francis J, Islam R, O'Connor D, Patey A, Ivers $N$, et al. A guide to using the theoretical domains framework of behaviour change to investigate implementation problems. Implement Sci. 2017;12(1):77.

24. Michie S, Johnston M, Abraham C, Lawton R, Parker D, Walker A. Making psychological theory useful for implementing evidence based practice: a consensus approach. Qual Saf Health Care. 2005;14(1):26-33.

25. Robroek SJ, van Lenthe FJ, van Empelen P, Burdorf A. Determinants of participation in worksite health promotion programmes: a systematic review. Int J Behav Nutr Phys Act. 2009;6(1):26.

26. Tricco AC, Lillie E, Zarin W, O'Brien KK, Colquhoun H, Levac D, et al. PRISMA extension for scoping reviews (PRISMA-SCR): checklist and explanation. Ann Intern Med. 2018;169(7):467-73.

27. Boland A, Cherry MG, Dickson R. Doing a systematic review: a student's guide. 2. ed. Los Angeles: SAGE; 2017.

28. Peters MDJ GC, Mclnerney P, Baldini Soares C, Khalil H, Parker D. Chapter 11: Scoping Reviews. 2017. In: Joanna Briggs institute Reviewer's manual [internet]. The Joanna Briggs institute. Available from: https://reviewersmanual.joannabriggs.org/

29. Arksey H, O'Malley L. Scoping studies: towards a methodological framework. Int J Soc Res Methodol. 2005;8(1):19-32

30. Cane J, O'Connor D, Michie S. Validation of the theoretical domains framework for use in behaviour change and implementation research. Implement Sci. 2012;7:37.

31. Weatherson KA, Gainforth HL, Jung ME. A theoretical analysis of the barriers and facilitators to the implementation of school-based physical activity policies in Canada: a mixed methods scoping review. Implement Sci. 2017;12(1):41.

32. Taylor WC, Horan A, Pinion C, Liehr P. Evaluation of booster breaks in the workplace. J Occup Environ Med. 2014;56(5):529-34.

33. Taylor WC, King KE, Shegog R, Paxton RJ, Evans-Hudnall GL, Rempel DM, et al. Booster breaks in the workplace: participants' perspectives on healthpromoting work breaks. Health Educ Res. 2013;28(3):414-25.

34. Tudor-Locke C, Hendrick CA, Duet MT, Swift DL, Schuna JM, Martin CK, et al. Implementation and adherence issues in a workplace treadmill desk intervention. Appl Physiol Nutr Metab. 2014;39(10):1104-11.

35. Justesen JB, Eskerod P, Christensen JR, Sjøgaard G. Implementing workplace health promotion - role of middle managers. Int J Workplace Health Manag. 2017;10(2):164-78

36. Kinnafick FE, Thogersen-Ntoumani C, Shepherd SO, Wilson OJ Wagenmakers AJM, Shaw CS. In it together: a qualitative evaluation of participant experiences of a 10-week, group-based, workplace HIIT program for insufficiently active adults. J Sport Exerc Psychol. 2018;40:1-10.

37. Lawton R, McEachan R, Jackson C, West R, Conner M. Intervention fidelity and effectiveness of a UK worksite physical activity intervention funded by the BUPA Foundation, UK. Health Promot Int. 2015;30(1):38-49.

38. Andersen LL, Zebis MK. Process evaluation of workplace interventions with physical exercise to reduce musculoskeletal disorders. Int J Rheumatol. 2014; 2014:761363.

39. Mayer JM, Nuzzo JL, Dagenais S. Use of participant focus groups to identify barriers and facilitators to worksite exercise therapy adherence in randomized controlled trials involving firefighters. Patient Prefer Adherence. 2013;7:207-15.

40. Bredahl TV, Saervoll CA, Kirkelund L, Sjogaard G, Andersen LL. When intervention meets organisation, a qualitative study of motivation and barriers to physical exercise at the workplace. ScientificWorldJournal. 2015; 2015:518561.

41. Taylor WC, Shegog R, Chen V, Rempel DM, Baun MP, Bush CL, et al. The booster break program: description and feasibility test of a worksite physical activity daily practice. Work. 2010;37(4):433-43.
42. Shepherd SO, Wilson OJ, Taylor AS, Thogersen-Ntoumani C, Adlan AM, Wagenmakers AJ, et al. Low-volume high-intensity interval training in a gym setting improves cardio-metabolic and psychological health. PLoS One. 2015:10(9):e0139056.

43. McEachan RR, Lawton RJ, Jackson C, Conner M, Meads DM, West RM. Testing a workplace physical activity intervention: a cluster randomized controlled trial. Int J Behav Nutr Phys Activity. 2011;8:29.

44. Andersen LL, Saervoll CA, Mortensen OS, Poulsen OM, Hannerz H, Zebis MK Effectiveness of small daily amounts of progressive resistance training for frequent neck/shoulder pain: randomised controlled trial. Pain. 2011;152(2):440-6.

45. Mayer JM, Quillen WS, Verna JL, Chen R, Lunseth P, Dagenais S. Impact of a supervised worksite exercise program on back and core muscular endurance in firefighters. Am J Health Promot: AJHP. 2015;29(3):165-72.

46. Andersen LL, Zebis MK, Pedersen MT, Roessler KK, Andersen $\mathrm{CH}$, Pedersen $\mathrm{MM}$, et al. Protocol for work place adjusted intelligent physical exercise reducing musculoskeletal pain in shoulder and neck (VIMS): a cluster randomized controlled trial. BMC Musculoskelet Disord. 2010;11:173.

47. Moher D, Liberati A, Tetzlaff J, Altman DG, Group P. Preferred reporting items for systematic reviews and meta-analyses: the PRISMA statement PLoS Med. 2009;6(7):e1000097.

48. Rogers EM. The diffusion of innovation 5th edition ed. New York: free press; 2003.

49. Kotter JP. Leading change - why transformation efforts fail. Harvard Bus Rev. 1995;73(2):59-67.

50. Durlak JA, DuPre EP. Implementation matters: a review of research on the influence of implementation on program outcomes and the factors affecting implementation. Am J Community Psychol. 2008;41(3-4):327.

51. Doherty $\mathrm{A}$, Jones SP, Chauhan U, Gibson JME. An integrative review of multicomponent weight management interventions for adults with intellectual disabilities. J Appl Res Intellect Disabil: JARID. 2018;31(Suppl 1):39-51.

52. Berlin C, Neumann WP, Theberge N, Ortengren R. 'Power base' tactics for workplace change - an interview study with industrial engineers and ergonomists. Ergonomics. 2017:60(5):613-27.

53. Berkhout AJ, Boumans NP, Mur I, Nijhuis FJ. Conditions for successfully implementing resident-oriented care in nursing homes. Scand J Caring Sci. 2009;23(2):298-308.

54. Wyatt KM, Brand S, Ashby-Pepper J, Abraham J, Fleming LE. Understanding how healthy workplaces are created: implications for developing a National Health Senice Healthy Workplace Program. Int J Health Serv. 2015;45(1):161-85.

55. Proctor E, Silmere H, Raghavan R, Hovmand P, Aarons G, Bunger A, et al. Outcomes for implementation research: conceptual distinctions, measurement challenges, and research agenda. Adm Policy Ment Health Ment Health Serv Res. 2011;38(2):65-76.

56. O'Connor S, Hanlon P, O'Donnell CA, Garcia S, Glanville J, Mair FS. Understanding factors affecting patient and public engagement and recruitment to digital health interventions: a systematic review of qualitative studies. BMC Med Inform Decis Mak. 2016;16(1):120.

57. Hoffmann TC, Glasziou PP, Boutron I, Milne R, Perera R, Moher D, et al. Better reporting of interventions: template for intervention description and replication (TIDieR) checklist and guide. BMJ : British Medical Journal. 2014; 348:g1687.

58. Nathan N, Elton B, Babic M, McCarthy N, Sutherland R, Presseau J, et al. Barriers and facilitators to the implementation of physical activity policies in schools: a systematic review. Prev Med. 2018;107:45-53.

59. Michie S, Pilling S, Garety P, Whitty P, Eccles MP, Johnston M, et al. Difficulties implementing a mental health guideline: an exploratory investigation using psychological theory. Implement Sci. 2007;2:8.

60. Dobson F, Bennell KL, French SD, Nicolson PJA, Klaasman RN, Holden MA, et al. Barriers and facilitators to exercise participation in people with hip and/ or knee osteoarthritis: synthesis of the literature using behavior change theory. Am J Phys Med Rehabil. 2016;95(5):372-89.

61. Quigley A, Baxter L, Keeler L, MacKay-Lyons M. Using the theoretical domains framework to identify barriers and facilitators to exercise among older adults living with HIV. AIDS Care. 2018:1-6.

62. French SD, Green SE, O'Connor DA, McKenzie JE, Francis JJ, Michie S, et al. Developing theory-informed behaviour change interventions to implement evidence into practice: a systematic approach using the theoretical domains framework. Implement Sci. 2012;7:38.

63. Morrison A, Polisena J, Husereau D, Moulton K, Clark M, Fiander M, et al. The effect of English-language restriction on systematic review-based metaanalyses: a systematic review of empirical studies. Int J Technol Assess Health Care. 2012;28(2):138-44. 
64. Wierenga D, Engbers LH, Van Empelen P, Duijts S, Hildebrandt VH, Van Mechelen W. What is actually measured in process evaluations for worksite health promotion programs: A systematic review. BMC Public Health. 2013;13(1):1190.

65. Michie S, van Stralen MM, West R. The behaviour change wheel: a new method for characterising and designing behaviour change interventions. Implement Sci. 2011;6:42.

\section{Publisher's Note}

Springer Nature remains neutral with regard to jurisdictional claims in published maps and institutional affiliations.

- fast, convenient online submission

- thorough peer review by experienced researchers in your field

- rapid publication on acceptance

- support for research data, including large and complex data types

- gold Open Access which fosters wider collaboration and increased citations

- maximum visibility for your research: over $100 \mathrm{M}$ website views per year

At $\mathrm{BMC}$, research is always in progress. 